\title{
Social Learning Platforms and the Flipped Classroom
}

\author{
Albin Wallace
}

\begin{abstract}
This paper examines the use of social learning platforms in conjunction with the emergent pedagogy of the 'flipped classroom'. In particular the attributes of the social learning platform "Edmodo" is considered alongside the changes in the way in which online learning environments are being implemented, especially within British education. Some observations are made regarding the use and usefulness of these platforms along with a consideration of the increasingly decentralized nature of education in the United Kingdom.
\end{abstract}

Index Terms-Education, Edmodo, Internet, learning platforms.

\section{INTRODUCTION}

Social learning platforms have a long history in education although they have been often referred to by many different names. Their immediate predecessors were the Managed Learning Environments (MLE) which morphed into Virtual Learning Environments (VLE), later to be known as learning platforms before becoming Personal Learning Networks (PLN). The latest incarnation of these platforms are webbased interfaces that mirror (and sometimes creatively distort) the classroom by providing online access to innovative collaboration tools in addition to traditional teaching tools such as tests, revision material and links to external webbased material. Following the trend of other popular social networking platforms such as Facebook they in turn have evolved into online social environments where students and teachers can communicate and engage in online dialogue in a safe and secure environment. Although social learning platforms are seen as tools for enhancing remote learning they are often also used within the school.

For many years now, use of these online virtual spaces in primary and secondary education has been determined by policies, strategies and frameworks that have been predominantly hierarchical and top-down, and which have relied heavily on organisational control and power structures to influence practice within the classroom [1]. Outcomes of research that evaluates the effectiveness of online platforms have been mixed [2]. Research by both academics and users within schools and higher education institutions has provided inconclusive results regarding educational effectiveness and organisational efficiencies. The limited, measurable impact of these platforms has been partially a reflection of the educational practices behind them. The practices that have emerged through the use of these online technologies have often not been coherent with the vision of the organizations that have mandated their use.

Manuscript received July 26, 2013; revised November 15, 2013.

A. Wallace is with The Education Fellowship, Titchmarsh, United Kingdom (e-mail: albinwallace@educationfellowship.net).
The emergence of more democratic approaches to education [3], along with the increasing decentralisation of educational power in the UK in recent times have revealed that a great deal of innovative classroom and pedagogical practice has actually been taking place over a number of years in our schools despite, rather than because of the National Strategies. In addition, the recent spontaneous and viral implementation of flipped classroom pedagogies and epistemologies has started to infiltrate the mainstream in British schools. As such, the traditional models of learning platform implementation are weakening at the same time and are possibly no longer sustainable in a country where the focus is rapidly moving away from centralised education policy towards a greater focus on teacher-led, innovative classroom practice.

The Education Fellowship (TEF) is a charity sponsoring academies based in England. It is a rapidly growing group of schools with both primary and secondary schools within the English education system. The Education Fellowship takes a teaching and learning focussed approach towards pedagogy, curriculum and school improvement, and adopted Edmodo at an early stage as its suggested social learning platform. The reasons behind this choice lie with the instructional design and underlying ontology of the platform itself. Edmodo embodies a democratic approach with its organisational structure and takes an educational grassroots approach towards systems' development and resource sharing. It has administrative and organisational functionality which actually reflects the natural rhythms and cultures of school classrooms. Many TEF teachers are implementing Edmodo in their teaching and learning design in a way that not only encompasses and embraces effective, existing models, but also acts as a catalyst and a driver for change by turning traditional instructional models on their heads by allowing children to more actively participate in their learning during the school day and also out of school. This also promotes the creation and distribution of information and knowledge in a wide range of learning contexts. The use of Edmodo in the classroom has not been a model imposed by TEF, but rather has been a quiet, educational revolution that has taken place at the classroom level, led by teachers and students alike.

It is well-established that cultural change in schools is strongly driven by classroom practice [4] and by teachers taking control over their own professional space and using evidence-based, action research models for teaching and learning. This in turn forms the basis for developing their learning platforms for instruction, collaboration and independent learning. Good teachers use Edmodo not just as an instructional device, but as a tool for both collaboration and communication. Edmodo provides a framework for learning that actively promotes and engages the teacher in risk-taking at both the strategic and tactical levels in the classroom within the spirit of social networking. 
One of the powerful aspects of social networking and the social media platforms that support these activities is that when integrated into effective classroom models, they can work together to help facilitate a sustained ecological change in classrooms, helping to raise standards, professionalise teachers, and motivate students by enabling a viable, highquality education that is not just aimed at promoting high standards in classrooms but also helping to increase levels of attendance and participation in school activities. The fact that Edmodo is being used by teachers to create communities of practice for themselves and children is a highly authentic and honest reflection of the natural interaction of teachers and children in the classroom. The best teaching, collaboration and affinity spaces for teachers are those that have emerged from the teacher groups themselves.

A good example of this in England is the increasing prevalence and success of Teachmeets; spontaneous, democratic unconferences that teachers are using to bring together like-minded people to share, collaborate and debate jointly to determine future educational strategies. It is highly likely that in the world of decentralised education, educational power will be once more invested in teachers. The eventual demise of national education strategies has meant a freeing up of the curriculum and subsequent empowerment of teachers, putting the locus of control back with the classroom professional and away from the centralised policymakers. One might speculate about the future of centralised education policy. The bureaucratisation of education is counter-productive when it comes to continuity of educational practice with national strategies fragmenting educational theory and distracting teachers from the core business of teaching.

In a way Edmodo can be seen as a subversive device that allows teachers to take part in a revolution in the ways in which classrooms and engagement with students are structured. The shape of learning may be radicalized and the way in which teachers and students interact driven by the influences of social media and their online communities. The context of Edmodo is not primarily technological. It is essentially a pedagogical and collaborative communication system that encourages a move away from an infrastructureheavy, technocratic education environment where technology takes centre stage. The virtual spaces are ones that are accessible through mobile, personal, portable networked devices. This will help ensure that the emergent revolution is one which has a serious, sustainable future, firmly grounded in popular, contemporary, transient and mutable technologies. The fundamental impact will be on the way in which we not just regard education, but the way in which we regard each other as human beings and the manner in which we interact and collaborate.

The flipped classroom is an emergent form of teaching and learning in which students watch instructional videos online and complete tasks set during lesson time. This pedagogy allows teachers to spend greater amounts of time tutoring students in place of lecturing them, benefitting children with a range of abilities, interests and needs.

The flipped classroom inverts the traditional model of teaching which has been to assign homework and revision out of school hours outside school, with class time being used for didactic instruction and assessments. In flipped classroom teaching, the students undertake investigation of content independently, often using video or other online media. Classroom time is used by students to undertake set tasks and do practical work. The teacher tutors the students as needed, allowing greater pedagogical space and time for differentiated educational intervention. Edmodo lends itself extremely well to be a platform through which the flipped classroom can be delivered, in conjunction with video-based content from YouTube, Khan Academy, O2 Learn or generated by the teachers themselves.

\section{ANALYSIS}

The figures within this paper show samples of the Edmodo communities of practice along with some data from a survey of 100 teachers' usage of Edmodo, demonstrating the year levels in which it was used and the comparative usefulness of its various features. The flipped classroom emerged from practice rather than from either theory or policy, and was quickly adopted within the schools by teachers who observed the effectiveness of the methodology, rather than being dictated by the school policy makers. Fig. 1 shows the rhizomic nature of the spread of the flipped classroom through the use of Edmodo, with large numbers of teachers using the technique within a very short period of time.

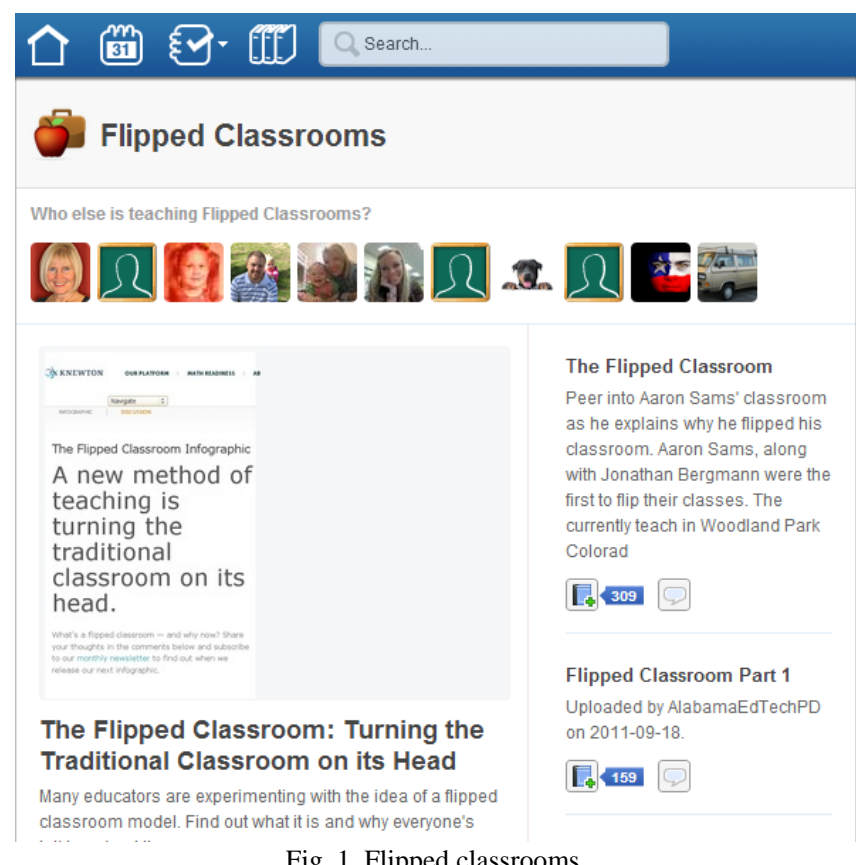

Fig. 1. Flipped classrooms.

A deeper trawl of Edmodo reveals high levels of appropriation by teachers in specific subject areas. By August 2013, over 100,000 teachers were engaged in the language arts online community of practice with lively discussions and debate over the flipped classroom model and other topics on interest, as seen in Fig. 2.

Amongst many other curriculum areas, social studies featured prominently too on Edmodo, with over 80,000 teachers worldwide engaging in online discussions. Fig. 3 shows the generosity of spirit amongst teachers within these communities, with resources being readily and openly shared. The similarities between Edmodo and Facebook are evident with threaded discussions going beyond the traditional discussion forums into a highly personalised and 
focused engagement.

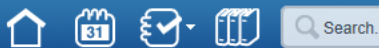 \\ Language Arts

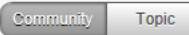

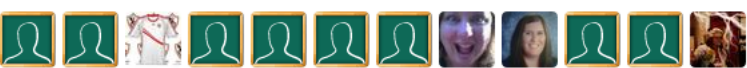 \\ type your note here. \\ Mrs. Peska to Language Arts \\ Whith \\ I m overnhelmed with the amount of awesome ways for students to create projects in $\mathrm{my}$ 6th grade Language Arts classroom I I am hoping for some guidance on what you think are the BEST outlets for student work as I plan for next year and subscriptions to ask for from my principal. I do use GLOGSTER already for biographies. Any other suggestions/project outlets are greatly appreciated! \\ 5 hours ago $\$$. \\ A. Mr. Johnston - Our students too are generating a ton of media. Our school has it's own youtube account which all devices are synched to. We use blogs from grade 5 and up for students to collect and curate their best work as part of their digital portfolio or learning journey. The blogging has been powerful, but supported primarily for teachers who are bloggers themselves. Offering in-service for this training too has been vital. If you'te considering blogging, wordpress and kidblogs are good platforms. 4 hours ago}

Fig. 2. Language arts.

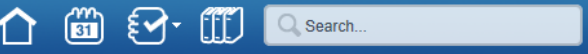

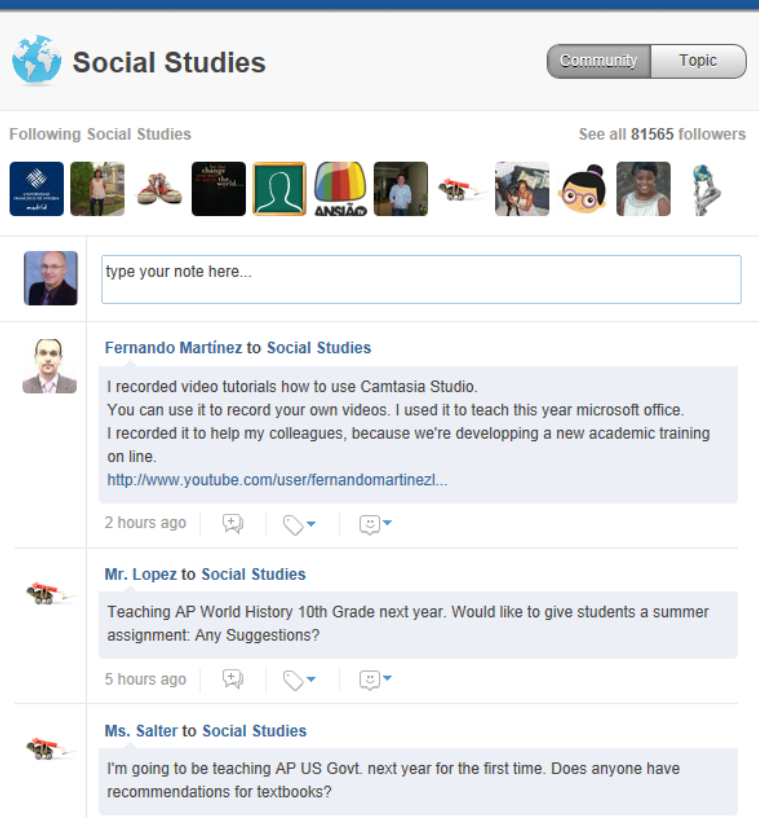

Fig. 3. Social studies.

If you are a teacher, which Key Stages do you teach?

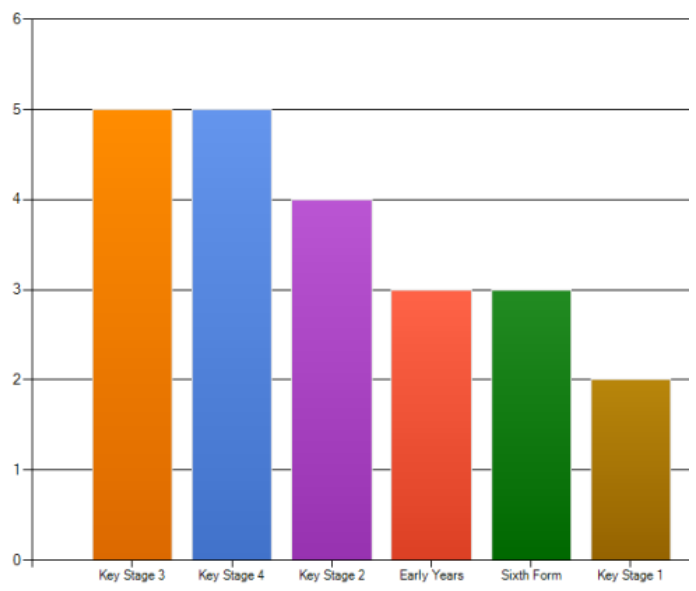

Fig. 4. Usage by year level
A survey of teachers within The Education Fellowship revealed the age groups using Edmodo for social learning. Fig. 4 shows that most usage occurred at Key Stage 2 (ages 8-11), Key Stage 3 (ages 12-14) and Key Stage 4 (ages 1011).

With respect to the perceived usefulness of Edmodo within the flipped classroom, the greatest amount of usefulness was indicated in the functionalities of posting messages and sharing folders, with the more performative functions such as setting assignments, quizzes and polls proving less popular. The survey results are indicated in Fig. 5.

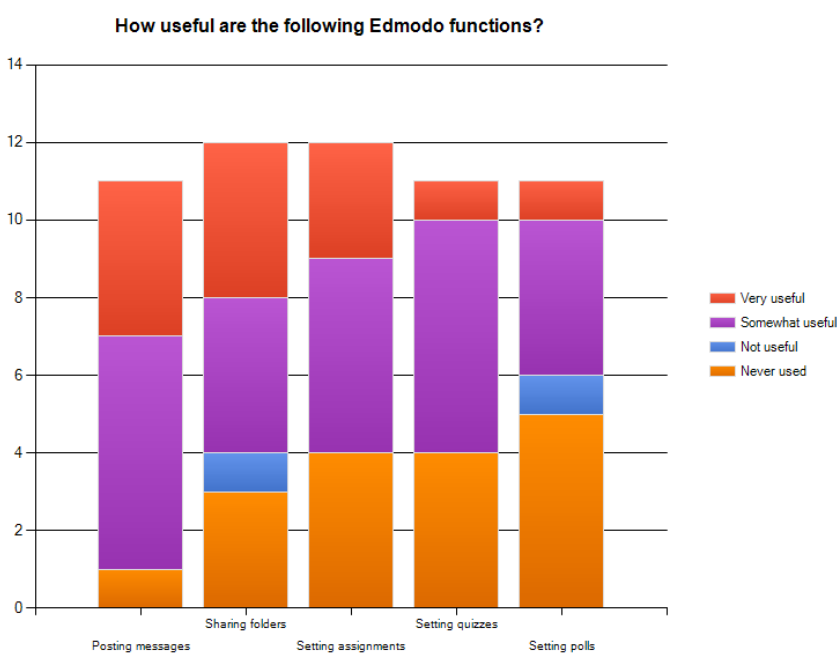

Fig. 5. Usefulness

\section{CONCLUSION}

The flipped classroom and the use of Edmodo exposes some ontological changes with respect to the use of digital technologies within education. The artificial duality of the "real" and online worlds [5] is revealed as being no longer relevant as the two spaces seamlessly integrate. This is particularly evident in the way in which video, text and instruction are balanced both synchronously and asynchronously according to need and expediency. Epistomologies also change with knowledge and understanding achieved through the flipped classroom challenging preconceptions about the roles of the teacher and the student and how these relationships become more complex and complementary in online spaces [6]. The traditional classroom habitus too is challenged with teachers' and students' sensibilities, dispositions and tastes being enriched and supported through the ability to more effectively cater for diverse learning styles, differentiation and mixed abilities.

\section{REFERENCES}

[1] DCSF, "Next generation learning 2008-2014 Strategy," Research reports, 2008.

[2] C. Jewitt, W. Clark, S. Banaji et al., "School use of learning platforms and associated technologies," thesis, London Knowledge Lab Institute of Education- University of London, 2010.

[3] S. Wilson, O. Liber, D. Griffiths, and M. Johnson, "Preparing for disruption: developing institutional capability for decentralized education technologies," in C. Montgomerie and J. Seale Eds., Proc. World Conference on Educational Multimedia, Hypermedia and Telecommunications, 2007, Chesapeake, VA: AACE, pp. 1386-1395. 
[4] M. Fullan, The New Meaning of Educational Change, Routledge, 2007.

[5] M. Prensky, "Digital Natives, Digital Immigrants Part 1," On the Horizon, vol. 9, issue 5, pp. 1-6, 2001

[6] E. Dobler, "Flattening classroom walls: Edmodo takes teaching and learning across the globe," Reading Today, vol. 29, no. 4, pp. 12-13, 2012.

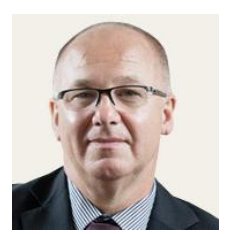

A. E. Wallace was born in England in 1957. He holds a bachelor's degree in arts, master's and doctoral degrees in education and a graduate diploma in educational technologies.

After spending 25 years working in the field of Information and Communications Technology (ICT) and education in Australia, he was employed for 3 years as ICT and Learning Technologies Manager of the South East
England Virtual Education Action Zone. With a firm belief that teachers are the key to achieving sustained ecological change in schools, he coordinated ICT professional development within SEEVEAZ. Between 2003 and 2012 he was Group ICT and e-Learning Director for the United Church Schools Trust and the United Learning Trust. He is now Executive Director of Research and Development for The Education Fellowship. He is the author of "Coherence of the Inchoate" (Cambridge Scholars, 2013).

Dr. Wallace is a fellow of the RSA, British Computer Society, NAACE and the Institute of Directors. He has a doctorate in education from the University of Sheffield where his thesis was on the formal and informal uses of the internet for learning. He has spoken at a number of international conferences on education and ICT. 